\title{
Algunas consideraciones sobre Silvano en Hispania
}

\author{
A. M. ${ }^{a}$ VÁZQUEZ HOYS *
}

Silvano era el adjetivo referente a la condición forestal o agreste de una divinidad probablemente originaria de los paises latinos, divinidad protectora en Roma de los árboles, bosques, campos, etc... y su fisonomía y funciones son análogas a las de otros dioses como Liber Pater, Faunus, Picus, Priapus, Vertumnus, etc. '.

Tuvo en el Panteón romano un rango inferior y no figura en ningún calendario romano ni tuvo culto oficial en Roma ni en las provincias del Imperio, aunque su culto estuvo muy extendido. El gran número de dedicaciones latinas a Silvano, más de 200 , aparecidas tanto en Italia como en las provincias de Europa occidental, muestran el destacado lugar que adquirió su culto desde fines de la República hasta fines del paganismo, principalmente en medios populares ${ }^{2}$.

Sobre el culto a Silvano en la Península Ibérica conocemos últimamente algunos trabajos ${ }^{3}$ tras los que queremos hacer algunas precisio-

* Departamento de Prehistoria e Historia Antigua. UNED, Madrid.

' Sobre Silvano, cfr., ALTHEIM, F., La religion romaine antique. París 1955; BAYET, J., Historie politique et psichologique de la religion romaine. París 1969 , págs. 131 SS.; BEAUJEAU, J., La religion romaine à l'apogée de l'Empire. I. I. Paris 1955, págs. 293 ss.; FerGuSON, J., The Religions of the Roman Empire. London 1974, pags. 67 y 71 y ss.; HILD, J. A., art. Silvanus en "Daremberg-Saglio-Pottier", Dictionnaire des Antiquités 4, 2, págs. 1341 45; también en "Pauly-Wissowa, Kroll-Mittelhans", Real Encyclopädie der classischen Altertumwissenschaft, art. Silvanus; ToutAIN, J., Les cultes paiens dans l'Empire romain. Roma 1967, t. I, págs. 260 ss.

2 Toutain, J., op. cit. págs. 260 ss.

${ }^{3}$ Pastor Muñz, M., "El culto al dios Silvano en Hispania. ¿Innovación o sincretismo?", Memorias de Historia Antigua, V. Oviedo 1981, págs. 103-114; MonTERo Herrero, S., "Los libertos y su culto a Silvano en Hispania", $A E A$ 58, núms. 1, 15 y 152. 1985, págs. 99-105. Gonzalez Roman, C., "Inscripciones romanas inéditas de la provincia de Jaén. III.", Florentia lliberritana, n. 1,1990 , Jaén 1991, n. ${ }^{\circ}$ I. 
nes dado que ya hace algunos años nosotros nos ocupamos de reunir las fuentes para el estudio de su culto en nuestra Península, asi como del de todas las divinidades hispanas ${ }^{4}$.

En Hispania la epigrafía dedicada a este dios es abundante. Conocemos 17 inscripciones, de ellas 10 halladas en la Tarraconense, de las que los autores que últimamente se han ocupado del culto a Silvano en nuestro país no recogen algunas, como las que incluimos con los números 9 y 10 , de la provincia de Cuenca ${ }^{5}$ o la número 16 , leída e interpretada últimamente por Encarnaçao ${ }^{6}$.

Las fuentes, pues, dedicadas a Silvano en Hispania son las siguientes:

\section{Tarraconense}
1. Tarraco (Tarragona): Siluanis/Aemilius/Adelphus/u(otum) s(oluit) l(ibens) ${ }^{?}$.

${ }^{4}$ Vazquez HoYs, A. M. ${ }^{3}$, La Religión romana en Hispania. Fuentes epigráficas, arqueológicas y numismáticas. Tesis Doctoral, Madrid (abrev. RRH). 1974, pub. 1982, t. II, cap. VIII: "Divinidades de los bosques, jardines y campos", págs. 508-9: Se recogen siete inscripciones (no las divinidades de culto imperial, que llevan el epiteto augustus-a, por lo tanto, ningún liberto, que encontramos solamente en las dedicaciones imperiales hechas a Silvano y que el Sr. Montero estudia. Y el cogrıomen Adelphus de la inscripción de Tarraco tal vez no baste para conocer si era liberto o no, ya que no se hace mención expresa de su condición social en la inscripción. Por tanto, creo que la afirmación que hacemos en RRH sobre que «las inscripciones a Silvano en Hispania no ostentan ninguna indicación de su clase social" es acertada. Nosotros recogimos solamente las dedicaciones a Silvano sin el epiteto augusto, que denota un culto imperial, ya que este ya to habia estudiado R. Etienne, como decimos en el prólogo de RRH. Y naturalmente tampoco hemos estudiado otros epitetos, que, como Pantheo parecen indicar un sincretismo con una divinidad oriental. El Sr. Montero Herrero incluye nuestra afirmación en su trabajo sin ningún comentario, cfr., nota núm. 9 , sin estimar, según creo, que nos referimos a inscripciones diferentes. En cuanto a las fuentes arqueológicas, también las recojo en RRH, t. II, 2 estatuas.

${ }^{5}$ Véase también sobre Silvano en Hispania, VAzQuez Hoys, A. M. ${ }^{a}$ " "La religión romana en Hispania. Análisis estadístico 1", Hispania Antiqua, VII. Valladolid 1977, págs. 4-45; id., "La religión romana en Hispania. Análisis estadístico II", en Hispania Antiqua, IX. Valladolid 1979, págs. 57-125; id., "La Religión romana en Hispania". Historia Universal de España y America. Madrid, Ed. Rialp, 1988, págs. $405-445$ y 458-460.

${ }^{6}$ EnCARnaÇAO, J., DE, Inscriçôes romanas do Conventus Pacensis. Coimbra 1984, núm. 61, pág. 109.

7 AE 1946, 197; VAzQUez Hors, A. M. ${ }^{a}$, La Religión romana en Hispania, Fuentes epjgráficas, arqueológicas y numismáticas, Madrid, Ed. Universidad Complutense, Tesis Doctorales núms. 114-82, (abreviada RRH), t. II, pág. 508; ALfóldY, G. Die Römischen Inschiriften von Tarraco, 2 vols. Berlín 1975, (abreviado RIT), núm. 49; MONTERO, núm. 1; RRH, núm. 2, siglo ॥ đ. C. GONZALEZ ROMÁN, pág. 149, nota 6. 
2. Tarraco (Tarragona). Siluano Aug(usto)/sacrum/pro salute imp(eratoris)/Caes(aris) Hadriani/Antonini Aug(usti) Pii P(atris) $P$ (atriae)/et liberorum eius/Atimetus lib(ertus)/tabul(arius) $P$ (rouinciae) H(ispaniae) C(iterioris) ${ }^{8}$.

3. Iluro (Mataró): Siluano/Aug(usto) sacr(rum)/P(ublius) Corneli/us Florus/VI Vir Aug(ustalis) ${ }^{9}$.

4. Barcino (Barcelona): D(is) D(eabusque)/Siluanis/M(arcus) Antonius/Chrysogonus/ u(otum) s(oluit) l(ibens) m(erito) ${ }^{10}$.

5. Dianium (Denia): /S/iluano/P(ublius) Bassu/lus /.../ribu /...// pro salut/em Adrianini ${ }^{11}$.

6. Vilvistre de los Nabos (Soria): Ucaer/n// us Culemqu/m//Edinis [f(ilius)]/Siluano/u(otum) s(oluit) l(ibens) m(erito) ${ }^{12}$.

7. Nieva de Cameros (Logroño): Siluano/Titullus/ Calaedico(n)/ Viam(i) f(ilius)/u(otum) s(oluit) l(ibens) m(erito) ${ }^{13}$.

8. Aquae Flaviae, Chaves (Portugal): Camalus M/ello/n/is Lim/ i/c/us S/il/ua/no//u(otum) s(oluit)/ a(nimo) I/(ibens) ${ }^{14}$.

9. Segobriga (prov. Cuenca): Siluan(o) ${ }^{15}$.

10. Osa de la Vega (prov. Cuenca): Viluano/G. An. Inne/nalis ${ }^{16}$ (Fig. 1).

\section{Bética}

11. Sevilla. Q(uinctus) M(arcus?)/These/us $D(e o)$ Silva/no a(nimo) l(ibens) $p$ (ro) s(uis) ${ }^{17}$.

${ }^{8}$ CIL 114.085 RIT núm. 4; Montero, núm. 2. Época de Antonio Pio.

${ }^{9}$ FABRE, G., y MEYER, M., Inscripciones Romanes de Mataro i la seva area. Mataró 1983, núm. 4; MONTERO, núm. 3. Mitad del siglo $॥$ d. C.

${ }^{10} \mathrm{CIL}$ II 4499 Mariner Bigorra, S., Inscripciones romanas de Barcelona, lapidarias y musivarias. Barcelona 1973, núm. 16; MonTERo, núm. 4. Gonzalez Roman nota 9, con numero de $\mathrm{Cl} / \mathrm{L} / /$ equivocado. Este autor da como cognomen Crescens, y también VIVES, n. ${ }^{\circ}$ 308. MONTERo lee Chrysogonus.

"EE IX, 356; MONTERO, núm. 5. Época de Hadriano.

12 Jimeno, A., Epigrafía romana de la provincia de Soria. Soria 1980, núm. 34. MONTERo, núm. 6. Siglo in d. C.

13 AE 1976, 331; EsPInOSA, U., Epigrafía romana de La Rioja. Logroño 1986, núm. 52;

MONTERO, núm. 7. Fines siglo i-mediados siglo $\| \mathrm{d}$. C.

${ }_{15}^{14} \mathrm{Cll}$ II 2496; RRH II, pág. 508, núm. 4; MONTERO, núm. 8.

${ }_{16}$ Almagro BasCh, M., Segobriga, II. Madrid 1984, pág. 92, núm. 21 (v-21) con foto.

93, Osuna, M., Museo de Cuenca. Madrid 1975, pág. 56; Almagro, Segobriga, II, pág.

${ }^{17} \mathrm{C}$ que $115388 ; R R H$ 1. I, pág. 509, núm. 1. Montero, núm. 9. Gonzalez Roman no la recoge, asi como algunas otras. 
A. M. ${ }^{a}$ VÁZQUEZ HOYS

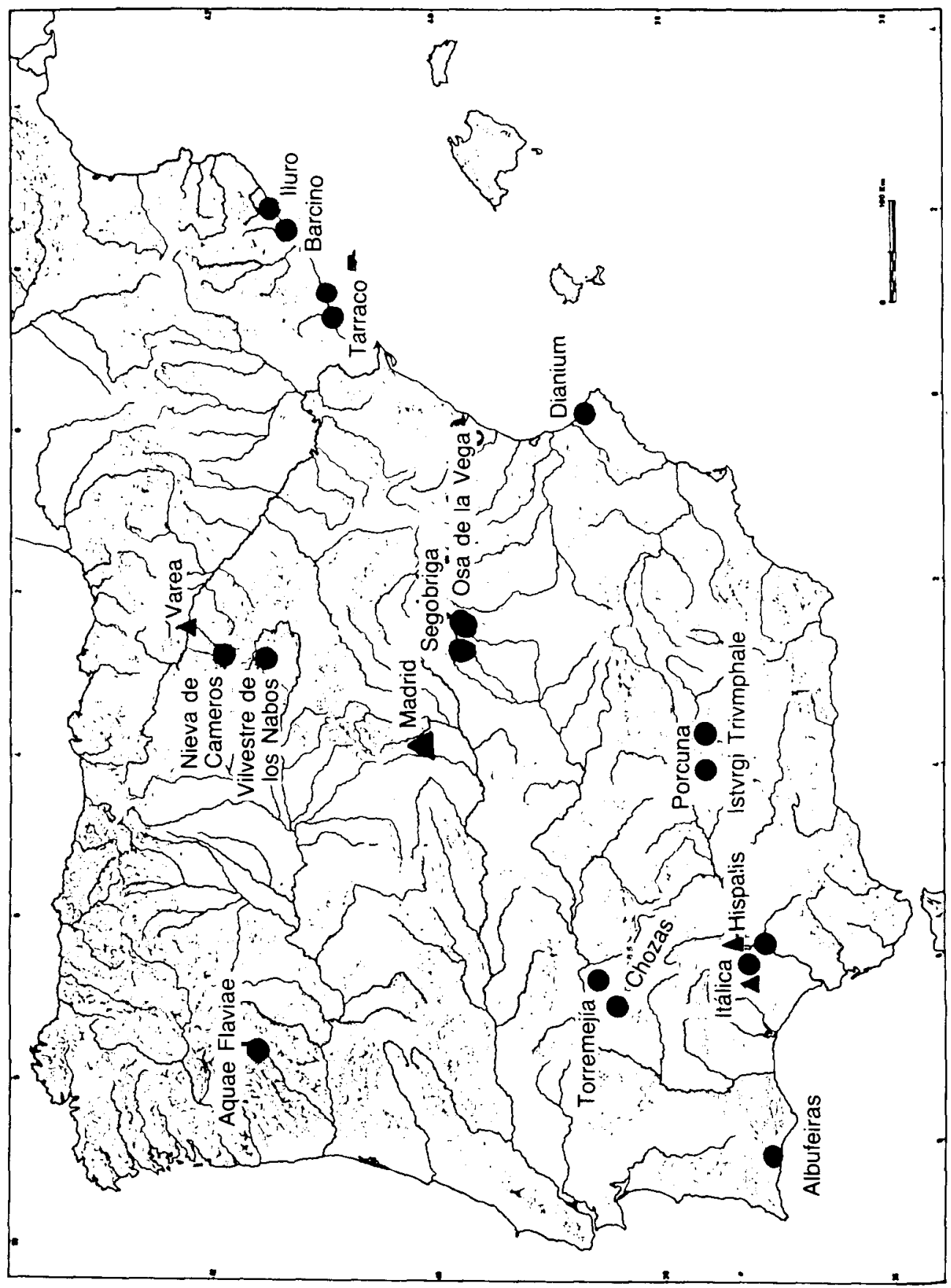


12. Italica. Pro salute Hadriani Aug(usti) et Sabinae Augustae n(ostrorum)/Siluano Pantheo Autarces/Sabinae Aug(ustae) n(ostrae) li(ertus) ex uoto ${ }^{18}$.

13. Porcuna (prov. Jaén): Numini Sancto Deo/ Siluano/Succesianus Au(usti) ser(us) ex uoto cum suis posuit ${ }^{19}$.

14. Isturgi Triumphale Los villares de Andújar (prov. Jaén): Silvano/ Aug(usto)/Runcani/us uic/tor 0.p./i. i. ci coh (ors)/ I Asturu/m ${ }^{19 b i s}$.

\section{Lusitania}

15. Torremejía (prov. Badajoz): Siluano/sacrum/L. lulius/lulianus $u(\text { otum })^{20}$.

16. Chozas (prov. Badajoz): Siluan(o)/ex uoto/ Modestini ${ }^{21}$.

17. Serros Altos(Albufeira): S(ilvano) (hedera) S(ancto?) (hedera), $T\left(\right.$ ?)/aram/Peculiaris ${ }^{22}$.

Es notable la decoración de este ara, con un puñal en relieve dentro de su vaina en el lado derecho y una cabra, también en relieve, en el lado izquierdo, en posición de saltar, cuyo vientre abultado es interpretado por Encarnaçao como signo de fecundidad o, simplemente, como falta de habilidad del artífice. Estos relieves ponen de manifiesto, para Encarnaçao, que la dedicatoria está hecha a Silvano S.T., claramente visible para Encarnaçao, para quien las letras que siguen al hombre del dios esconden un epiteto desconocido. También para este autor, Peculiaris es un nombre latino del que hay otros ejemplos en Lusitania, y no sería extraño que se tratase de un esclavo. Para Hübner se fecha en el siglo II, d. C. ${ }^{23}$.

18 BRAH 64, 1914, 535; Montero, núm. 10. Época de Adriano. Mangas, op. cit., en nota 33 infra, n. 5 , reconstruye $n$ (ostrae). Nosotros CANTO, A.: Epigrafía romana de Itálica, Madrid 1985, n. ${ }^{\circ} 35$

${ }^{19}$ HaE 2322; $R R H$ t. II, pág. 508, núm. 1; MONTERo, núm. 11.

196is GONZALEZ ROMÁN, C. op. cit., n. ${ }^{\circ}$ I y lám. I, donde se aprecia la evidencia de esta nueva lectura, que el mismo autor nos ha comunicado.

${ }^{20}$ BRAH 29, 1896, 257; RRH t. Il, pág. 509, núm. 6; Montero, núm. 12.

${ }^{21}$ CM Badajoz 424; RRH t. Il, pág. 509, núm. 5; Montero, núm. 13.

22 EncarnaçaO, J. DE, Inscriçoes romanas do Conventus Pacensis. Coimbra 1984, núm. 61, pág. 109. También leída por FIGUEIREDo (B. DE), RArq., III, 1889, pág. 119: (Slancto) S(ilvano) I(nvicto); CIL II 5138 (también ILER, núm. 477): S(aluti) S(anctae) D(eae); LEITE DE

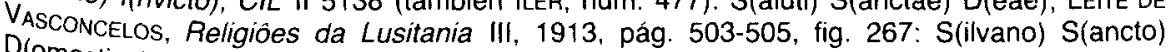
$\mathrm{D}$ (omestico) o restituyendo la última abreviatura por D(ianae).

${ }^{23} \mathrm{Cfr}$. asimismo, EnCARnACAO, J. DE, en Studia Palaeohispanica, Actas del IV Coloquio Sobre lenguas y culturas paloehispánicas. Vitori-Gasteiz 1985. Vitoria 1987, págs. 305-310, pág. 307. 
Estas inscripciones son en su mayor parte, de época imperial, sobre todo tenemos fechadas algunas del siglo II d. C., (cuadro 1), por lo que para Montero y Pastor Muñoz esta es la época de mayor auge del culto a Silvano en Hispania. Evidentemente, si tenemos en cuenta no solo el culto de Silvano sino el de todas las divinidades hispanorromanas, como hemos hecho nosotros en diferentes ocasiones, esto es algo normal, ya que esta es la tónica general en lo referente a las divinidades romanas en nuestra Península, por lo que no se trata de un hecho significativo ${ }^{24}$. Tal es el caso, por ejemplo, del culto a Júpiter ${ }^{25}$ o de Diana ${ }^{26}$. Hay que tener en cuenta al referirnos a estas cronologías, que son muy imprecisas, ya que nuestros elementos de datación para las inscripciones son muy amplios cronológicamente ${ }^{27}$. $Y$ también que es a fines del siglo 1 d. C. y siglo $\|$ cuando ese auge de dedicaciones religiosas a divinidades romanas tiene lugar en Hispania, tal vez por diversas causas:

1. Es ahora cuando puede decirse que hay una mayor romanización de Hispania, después de los problemas de la resistencia a la romanización que se constatan en algunas regiones al menos hasta la época Flavia, con la pervivencia de estructuras sociales y religiosas prerromanas (tanto indígenas como orientales, helenísticas o púnicas ${ }^{28}$, que sabemos no desaparecen totalmente y aflorarán nuevamente unos siglos después ${ }^{29}$.

${ }^{24}$ VAzQueZ Hors, A. M. ${ }^{\text {a }}$ "Consideraciones estadísticas sobre la Religión Romana en Hispania», Symposio sobre la Religión romana en Hispania. Madrid, Ministerio de Cultura, 1981, págs. 165-176; id. "Rapproche statistique sur la Religion romaine en Espagne", Colloque International sur l'Actualité de l'Antiquité, Toulouse, diciembre 1985 (pub. 1989, págs. 189-197.

${ }_{25}$ VAzouez HoYs, A. M. ${ }^{a}$, "El culto de Júpiter en Hispania". Cuadernos de Filología Clásica, XVIII, 1983, págs. 83-205.

${ }^{26}$ VAzQuez HoYs, A. M. ${ }^{2}$, "La Diana Hispánica", Diputación de Cuenca. En prensa.

${ }^{27}$ Como bien reconoce, también ENCARNACAO, J. DE, cfr. su articulo en Biblos, LXII, cit. en nota infra.

${ }^{28}$ VAzQuez HoYs, A. M. ${ }^{a}$, "La tradición religiosa del mundo mediterráneo en la Bética y la percepción de los cultos romanos", I Congreso Internacional sobre el Estrecho de gibraltar. Ceuta, noviembre 1987, págs. 845-854; id., "La Religón romana en la Bética y el sustrato prerromano", I Congreso de Historia Antigua de Andalucia, Córdoba 7-10 abril 1988, en presa; id., "Algunos problemas de la epigrafía religiosa hispanorromana, Col.loqui internacional dÉpigrafia, Culte i Societat en Occident. Tarragona, 6-8 octubre 1988, en prensa; id., "Lixus en el panorama religioso fenicio de Occidente", Tanger 7-11 noviembre 1989. Congreso Internacional Lixus, bilan et perspectives; id., "L'activité commerciale du temple tyrien de melkart et son expansion maritime: Un possible precedent biblique", Xth International Colloquium: "Phoenicia and the Bible. Archaelogy, History, Epigraphy". Groupe de contacts interuniversitaires d'études phéniciennes et puniques. Katholieke Universiteit. Leuven, febrero 1990; id., "Los oráculos y su "poder". El sueño de Jacob, el poder oracular de Herakles y el sueño de César: Coincidencias o empresas comerciales?", Homenaje a J. M. Blázquez. Departamento de $\mathrm{H}^{\text {a }}$ Antigua. Universidad Complutense. Madrid 1990, en 
2. Porque es un momento en el que el Culto Imperial parece no haber sustituido a los antiguos dioses romanos en toda su plenitud en nuestra Península, lo que ha permitido pervivir estos cultos romanos. Vemos, de todas formas, en esta época, que ya comienzan a encontrarSe, cada vez más, la divinidades imperiales ${ }^{30}$.

Por lo que se refiere al culto de Silvano en Hispania, no diríamos que "determinadas divinidades romanas, como la propia Diana a los Lares... usurparon las funciones de Silvano en Hispania" 31 , puesto que los ámbitos de extensión del culto de Diana y Silvano contrastado por la epigrafia casi coinciden geográficamente ${ }^{32}$.

En nuestra opinión, lo más interesante de las inscripciones de los libertos a Silvano en Hispania es que los dedicantes, a juzgar por sus cognomina, son griegos $u$ orientales. $Y$ tal vez se estan dirigiendo, al hacer sus dedicaciones, más que a un dios «imperial» romano, a una divinidad que ocupaba el ámbito de un dios prerromano mágico y salutífero, con fuertes rasgos orientales. Al mismo Pan griego, que era un dios Cosmogónico, evidente en el epíteto Pantheus de Italica. En este periodo encontramos en el mundo romano un renacimiento del orfismo que está atestiguado por los escritos de los filósofos y por toda la literatura crisitana recogida en los papiros mágicos. Fue una época caracterizada por la reavivación de los cultos mistéricos, particularmente del mitraismo, pero fue también la época del gnosticismo cristiano. Era el momento en que la religión universal helenística, el «panteismo solar», que Wendland, en su obra sobre la cultura helenistico-romana define como uforma final de la historia de las religiones antiguas» ${ }^{33}$. Esta evolución y transforma-

Prensa; id., "El comercio entre Hispania y Mauritania y el templo de Hércules-Melkart en

Gades, en época de luba II y Plolomeo", II Congreso El Estrecho de Gibraltar. Ceuta,

noviembre 1990 , en prensa.

29 VAZOUEZ HoYS, A. M. ${ }^{\text {, }}$ "Algunas consideraciones sobre cultos locales en la Hispania

romana", en Memorias de Historia Antigua, V. Oviedo 1981, págs. 41-50.

${ }^{30}$ Vazquez Hoys, A. M. ${ }^{2}$ y Del Hoyo Calleja, J., "Las divinidades romanas en Hispania y el problema de la romanización", / Congreso de Historia Peninsular. Coimbra 1990, en
prensa.

${ }_{32}$ Cfr. Montero, op. cit., pág. 104.

32 VAZQUEZ HOYS, A. M. A, "La Diana hispánica", en prensa.

${ }^{33}$ Cfr. Leisegang, $H$., "The Mystery of the Serpent", The Mysteries. Papers from the págs Yearbooks, Bollingen Series 2. t. Il, Princeton University Press 1955, págs. 194-260, págs. 218-219 y nota 12. Sobre Pantheo cfr. Mangas ManjarRÉs, J.: "Pantheus en HispaGià, González Román, C. (ed.): La Bética en su problemática histórica, Universidad de WEnada, 1991, págs. 111-131. La relación de los Symplemata Panteha", estudiados por ter má. S. en Germania X, 1926, pág. 130 ss., sin duda amuletos, es evidente con el carácGAS máico-apotropaico de Silvano, al que más abajo nos referimos. La utilización por MANGAS, op. cit. pág. 127 de la palabra «iglesia" en relación con la reunión de los fieles de 


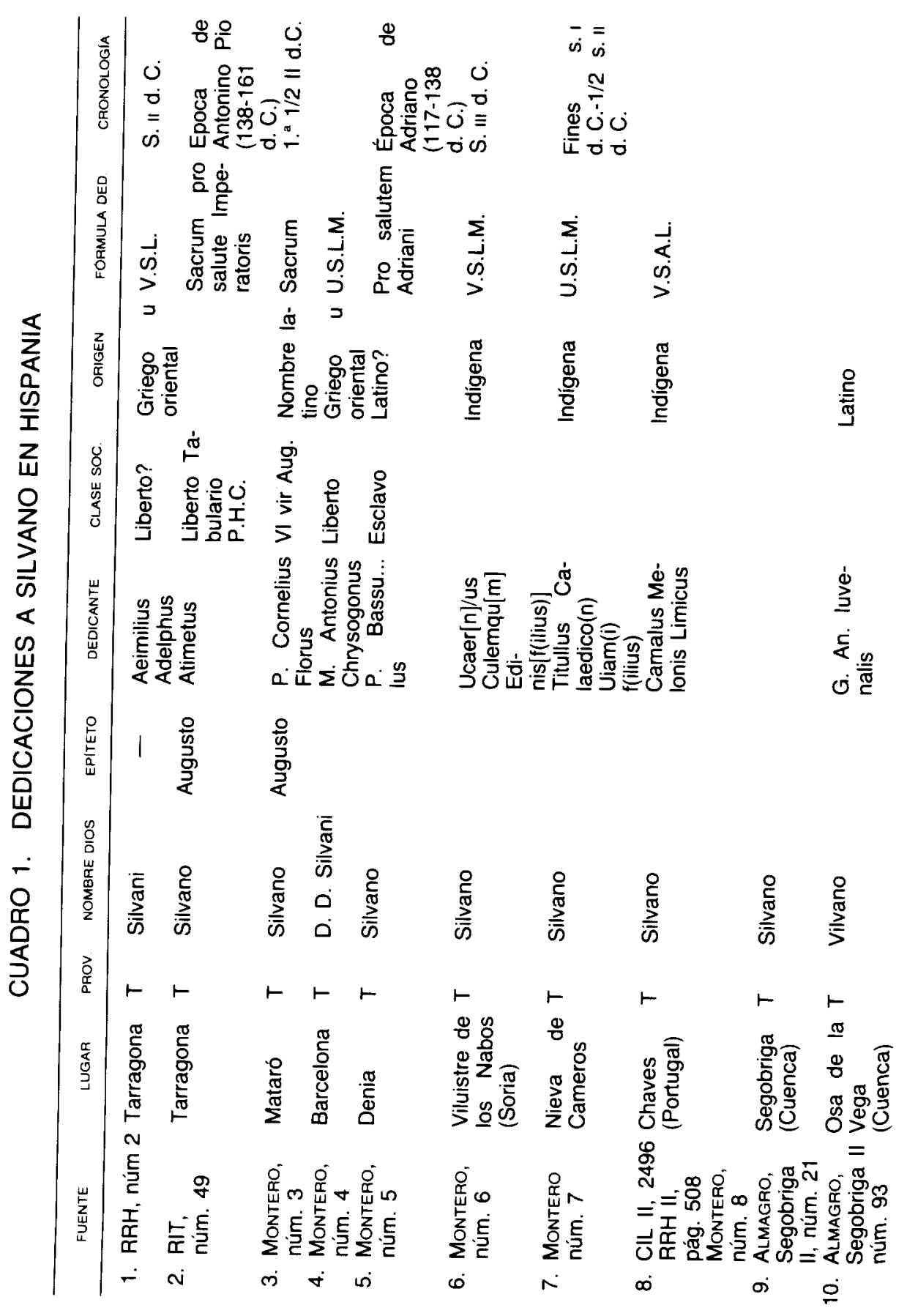




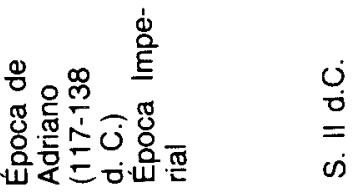

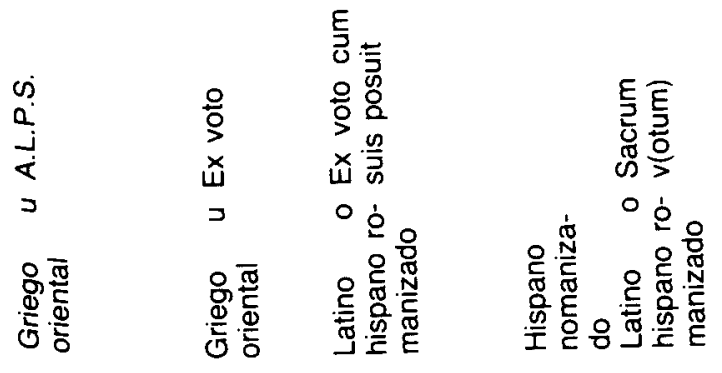

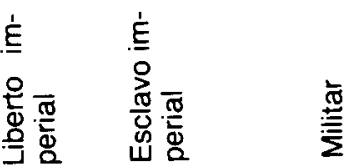

$\frac{1}{9}$

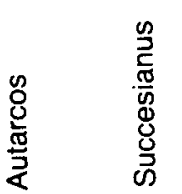

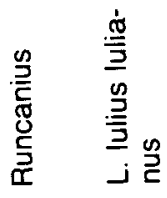

용

凶ั



$\dot{q}$

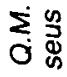

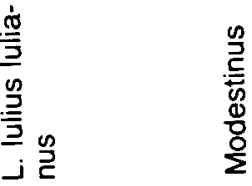

$\frac{\pi}{\pi}$
$\frac{\pi}{8}$
$\frac{\pi}{0}$
$\frac{\pi}{0}$

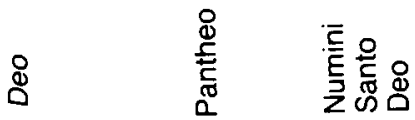

虽
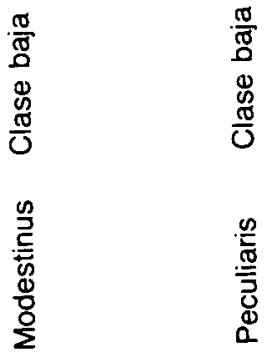

$\frac{8}{\frac{0}{0}}$

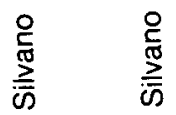

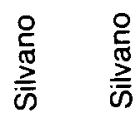

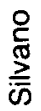

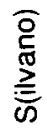

$\infty$

$\infty$

$\infty$

$\infty$



郶

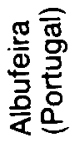

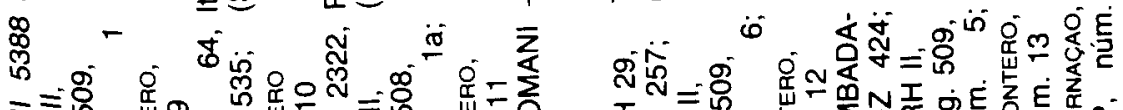

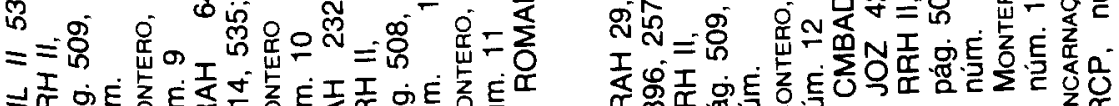

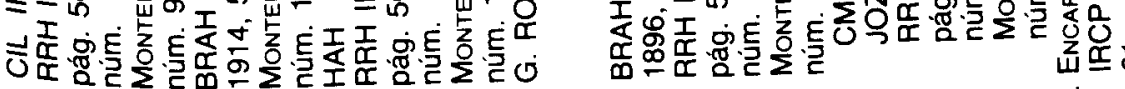

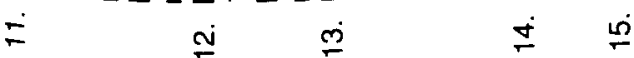

$\stackrel{\dot{\varphi}}{\dot{\varphi}}$ 

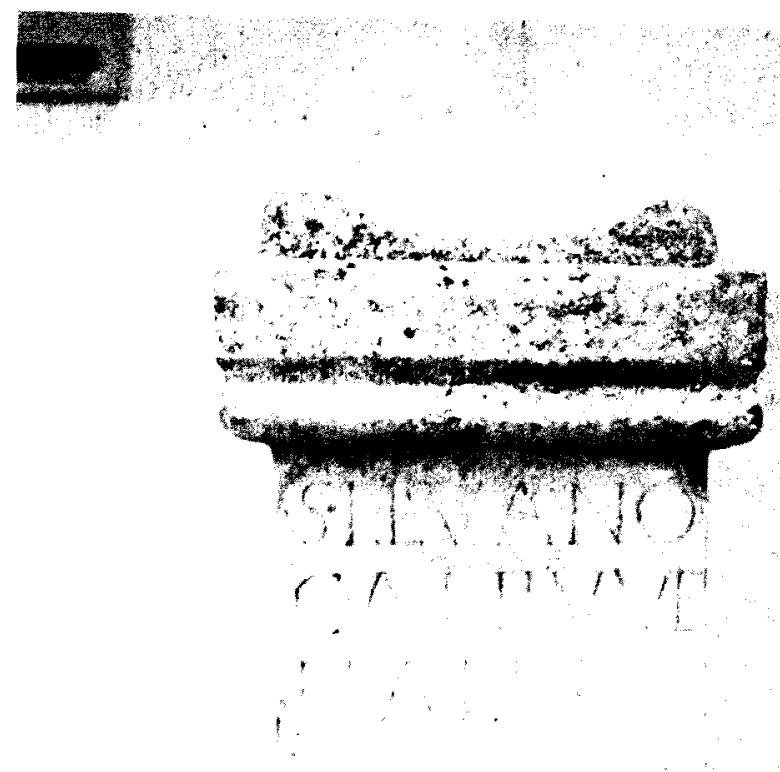

4
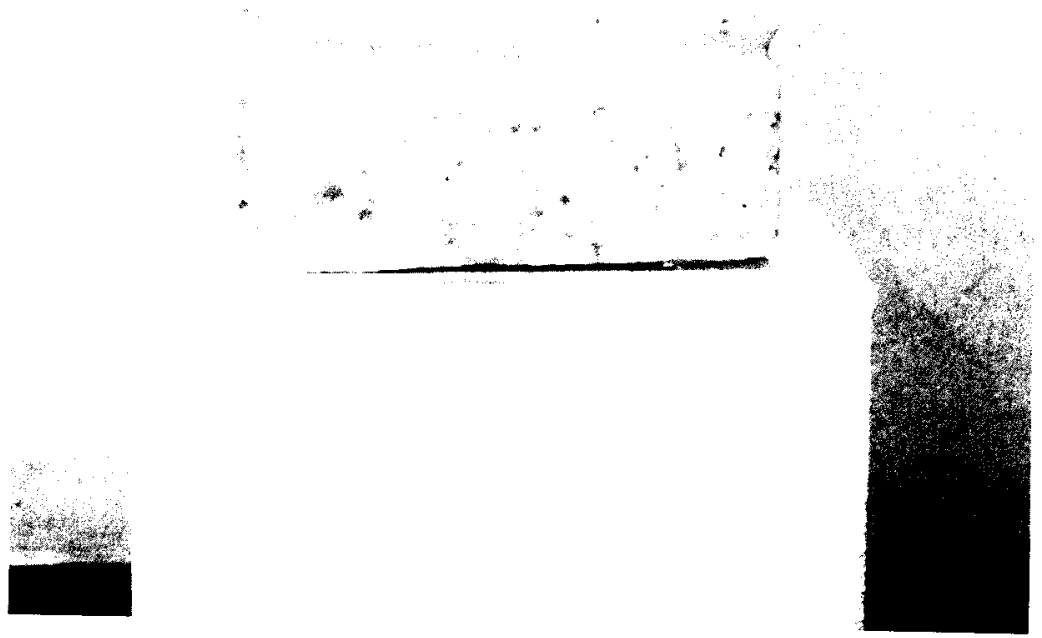

Fig. 1. Ara dedicada a Silvano. Museo Arqueológico de Cuenca. (Foto J. del Hoyo). 


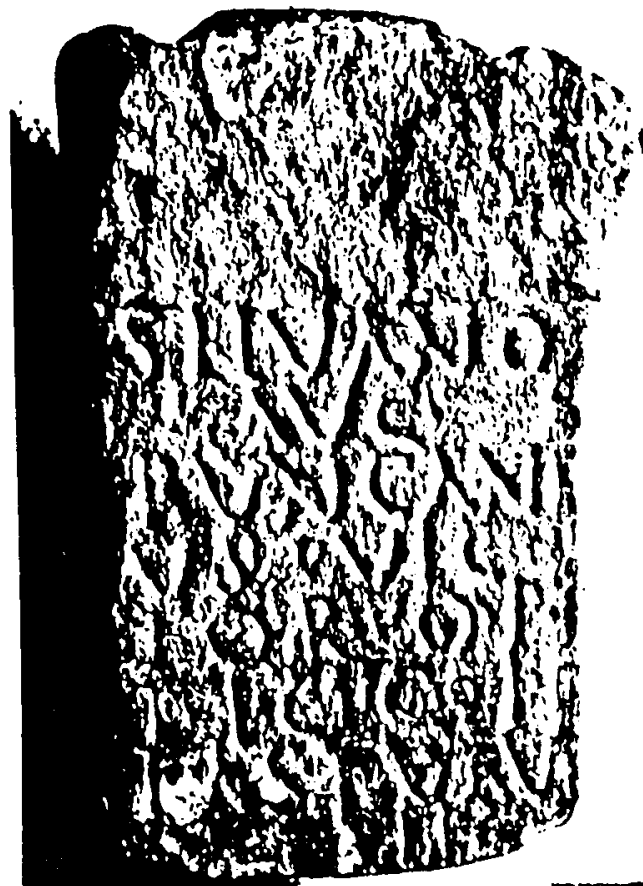

Fig. 2. Ara votiva procedente de los alrededores de Andújar. Sg. GoNzÁlez Román.

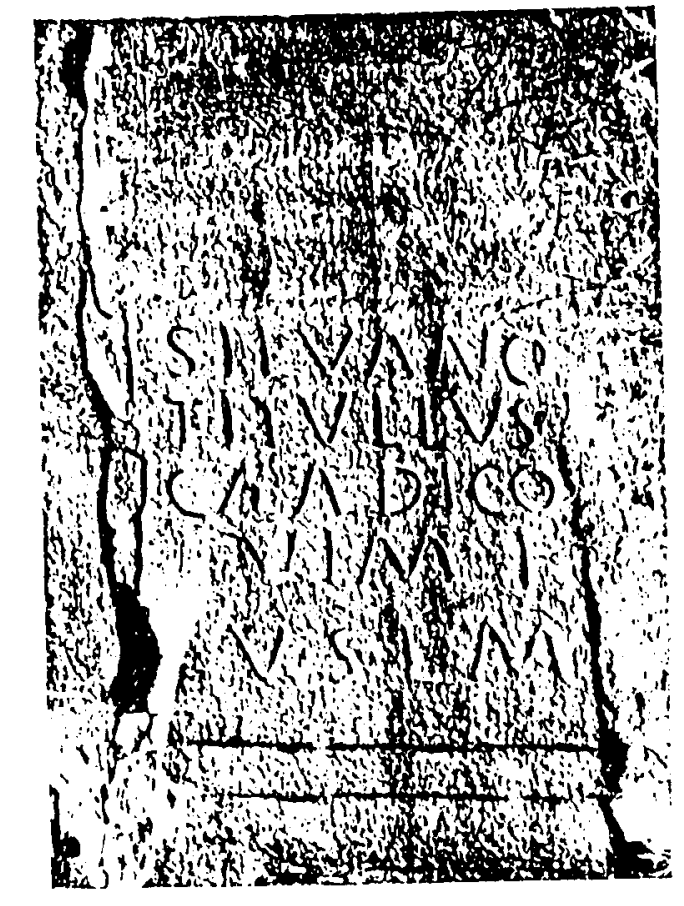

Fig. 3. Ara votiva procedente de Nieva de Cameros, sg. Garabito, T.Solovera, E., "Aras y estelas romanas del territorio berón», Durius, 1975 , págs. 324 y ss., n. IV, pág. 334. 


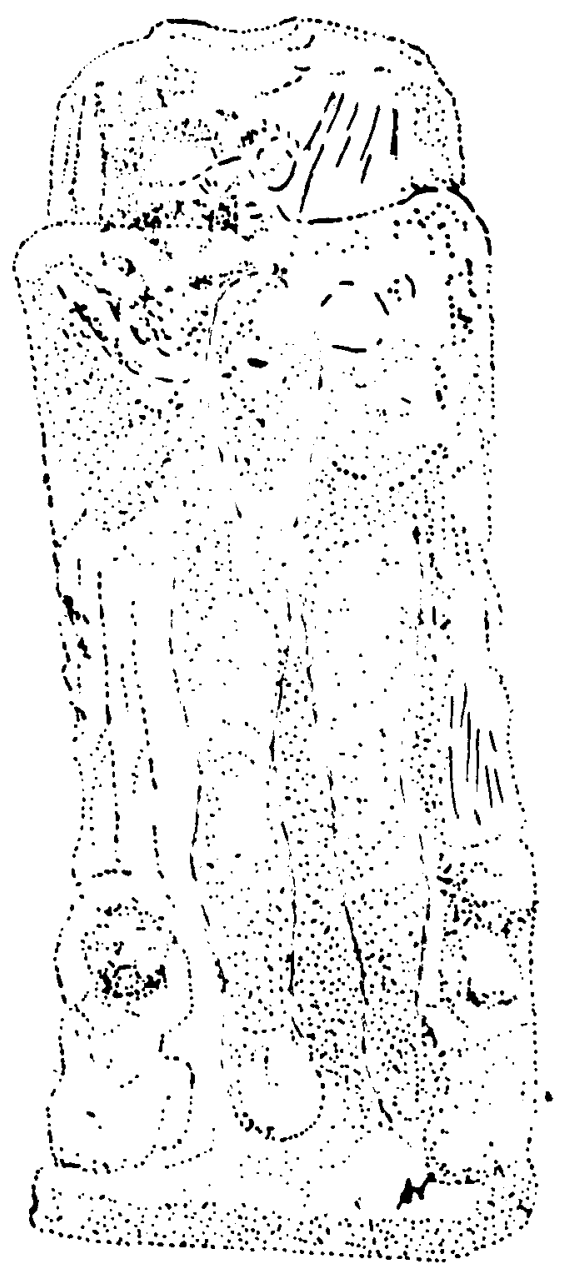

Fig. 4. Príapo. Piedra arenisca de las canteras de Montjuich. A.2,15. Hallado en Hostafranch, barrio periférico de Barcelona, en 1848. Barcelona, Museo Arqueológico número 1.161. La figura de Priapo está concebida de la forma habitual, con sus vestiduras remangadas, decubriendo sus piernas y el miembro viril y llevando en el halda flores y frutos alusivos a su carácter de deidad fecundante. A sus pies, ocultando sus cabecitas en el vuelo del chitón hay dos niños que juegan, al parecer, con un conejo y una pantera y otro juega sobre el pecho del dios. S. II d.C avanzado. Garcia y Bellido, A.: Esculturas, número 101, lámina 82. 
ción de Silvano desde los primeros tiempos romanos hasta la época imperial se aprecia también en la inscripción dedicada por Autarces, al confiarle este la salud de la emperatriz Sabina. Bien es sabido que el culto a Silvano según Catón, estuvo cerrado siempre a las mujeres: «...mulier ad eam rem diuinam ne adsit neve adeat ${ }^{34}$ como los hombre estaban excluidos de los cultos a Bona Dea ${ }^{35}$. De todas formas, hay que tener en cuenta que de las diecisiete inscripciones encontradas en la Península, dedicadas a Silvano, casi la tercera parte estan dedicadas por libertos (o posibles libertos, con onomástica oriental) (Cuadro núm. 1), lo que indicaría esta evolución de la religión de Silvano, no solo desde ser adorado por unas clases sociales bajas, más o menos escasas de recursos, sino hasta ver introducida en su culto la poderosa clase de los libertos imperiales, que manejaban las finanzas del Emperador.

Creo que tampoco se ha incidido, por parte de ninguno de los autores mencionados, sobre el caracter "mágico-apotropaico" de Silvano. Este dios, que recibia ofrendas junto con Tellus: "Tellurem porco, Silvanum lacte piabant" ${ }^{36}$ es, como bien sabemos, el dios de los límites, de los mojones, "tutor finium" le llama Horacio ${ }^{37}$, mágicos y protectores por sus fórmulas y representaciones de los dioses que impedían con su fuer$\mathrm{za}$ que pudiesen ser movidos ${ }^{38}$. Y por extensión, protegían toda la propiedad y más aún, y por extensión, el Imperio y la casa imperial. Tal vez a esta costumbre se deba la gran cantidad de libertos del Emperador que le ofrecen dedicaciones, en el “ámbito doméstico imperial». La palabra numen de la inscripción de Porcuna, seguida del nombre de la divinidad, Sería, para Meslin, la prueba de que ese dios definía una voluntad divina que se traducía por una acción eficaz ${ }^{39}$. Esta es, posiblemente, la razón por la que su nombre aparece en plural, como en el conocido texto de Lucano ${ }^{40}$, que relata la tala de un bosque por Cesar, en las proximidades de Marsella, al comiezo de la Guerra Civil:

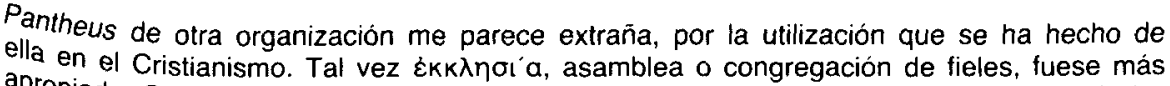
apropiada. Sobre los libertos cfr. SERRANo DELGADO, J.M.: Status y promoción social de los libertos en Hispania romana. Sevilla, 1988.

${ }_{35}^{34}$ CAT, De agr., loc. cit., Sachol Juv. VI 447, tab. CIL VI, 579.

${ }^{35} \mathrm{ClC}$. Har. resp. 37.

${ }^{36}$ HORAT, EPOD. II, 1, 1, 143.

37 Epod. II, 22.

38 HORAT, EDod. II, 27. pág. 201.

MESLIN, A., L'Homme romain des origines au $1 .^{e r}$ siècle de notre ère. Paris 1978.

${ }^{40}$ Lucano, La Farsalia, 3, 399 ss.
} 


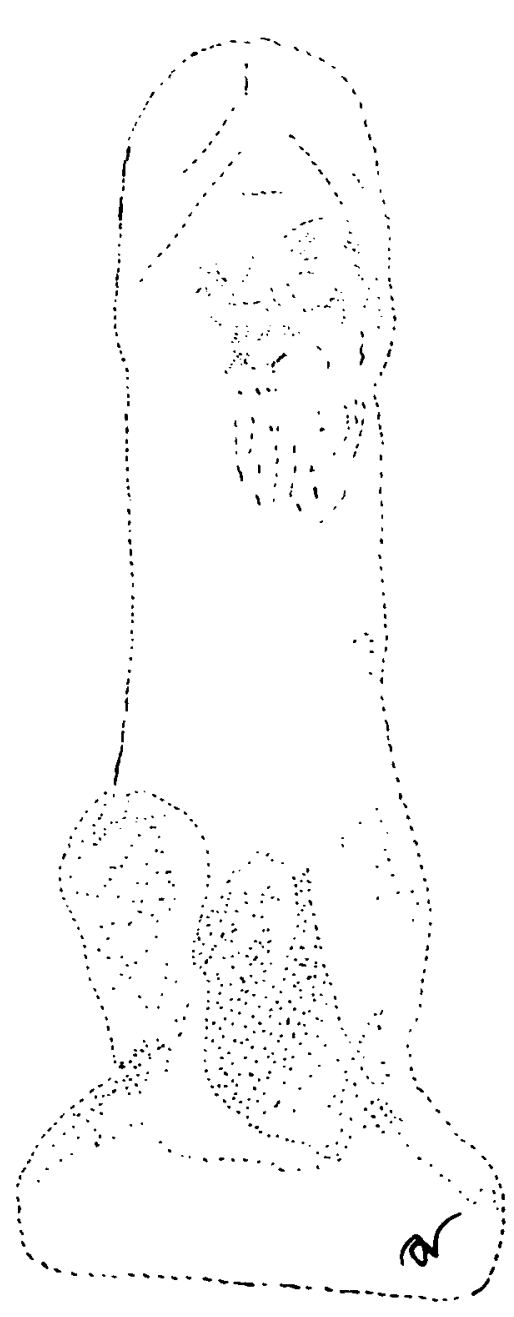

Fig. 5. Priapo. Marmol blanco. A.0,35 centímetros. Sin procedencia, pero parece local. Tarragona, Museo Arqueológico número 518. La deidad de los jardines y viñedos se nos presentan aquí de una forma insólita, convertida en un enorme falo que se sostiene, al parecer, sobre unos pies de macho cabrío. El falo termina en una cabeza humana rematada por el glande, que hace de gorro o barbada y con cierto gesto bonachón, según costumbre. GaRcia y BeLLIDO: Esculturas, número 102, lámina 82. 
«Habia un bosque sagrado, jamás violado desde largo tiempo, que ceñia con sus ramas entrelazadas un ambiente oscuro y gélidas umbrías, impenetrables al sol en sus profundidad. No lo ocupan los Panes ni los Silvanos y Ninfas, señores de las selvas, sino santuarios de unos dioses bárbaros en su culto..."

Recordemos, asímismo, que también fue conocido Silvano por su función oracular y que se le relaciona, como divinidad infernal protectora de los muertos con el galo Sucellus y el lobo ${ }^{41}$.

En cuanto a los epítetos, recordemos que a menudo encontramos deus acompañando las inscripciones de este dios. La presencia de esta palabra en las inscripciones se ha tenido por índice de poca romanización. Por ejemplo en el caso de la inscripción a una deidad lusitana, adorada en Miróbriga de los Célticos. Este santuario, aunque de época romana, estaría consagrado ${ }^{42}$ a una deidad lusitana, equivalente al EsCulapio griego. Esto se desprende de la inscripción Aesculapio/deo/C. Atticus lanuarius/medicus pacensis/testamenteo legavitob merita splendi/ dissimi ordinis/quod ei quinquatri/um praestiterit/Flabius Isas/f(aciendum)

La presencia del epíteto deus en esta inscripción, como ya indicó $S$. Lambrino ${ }^{43}$ significaria que se trata de una deidad indígena identificada con Esculapio.

Precisamente deus acompaña frecuentemente a deidades indígenas asimiladas a otras del panteón grecorromano. Baste recordar como ejemplo alguno de los publicados por A. Rodríguez Colmenero ${ }^{44}$ como la inscripción I(ovi) O(ptimo) M(aximo) / Rivo / Febo(que) D(eo), de Vila Real (Portugal).

${ }^{41}$ Livio II, 7, 2; Dion. Hall. V, 16; Val. Max. I, 8, 5; Cic. Div. I, 45; Nat. Deor. II, 2; III, 6: AUR, VICT. Orig. 4. Sobre Sucellus en Hispania, cfr. ORTEGO, T., Encuentro con una dama ibérica y con el falo Sucellus, Boletín de la Asociación de Amigos de la Arqueología, 9 , 1978 , 33 ss; también GARCIA BELLIDO, A. en AEA XXIX, 1966, págs. 125-129, revisa sobre todo el aspecto infernal de protector de los muertos de Silvano.

${ }^{42}$ Según Blazouez, J. M. ${ }^{a}$ y Garcia-Gelabert, M. ${ }^{a}$ P., "Nuevas aportaciones a las religiones primirivas de Hispania". Espacio, Tiempo y Forma, serie 11,1 , Historia Antigua, Homenaje al profesor Eduardo Aipoll Perelló, Uned 1988, págs. 153-183.

$d E_{s p}$ "Les cultes indigènes en Spagne sous Trajan et Hadrien", Les empereus romains 44

del "Un importante grupo de nuevos teónimos galaicos", Studia palaeohispanica, Actas 328 núm. Coquio sobre lenguas y culturas paleo-hispánicas (Veleia 2-3). Vitoria 1987, pág. 


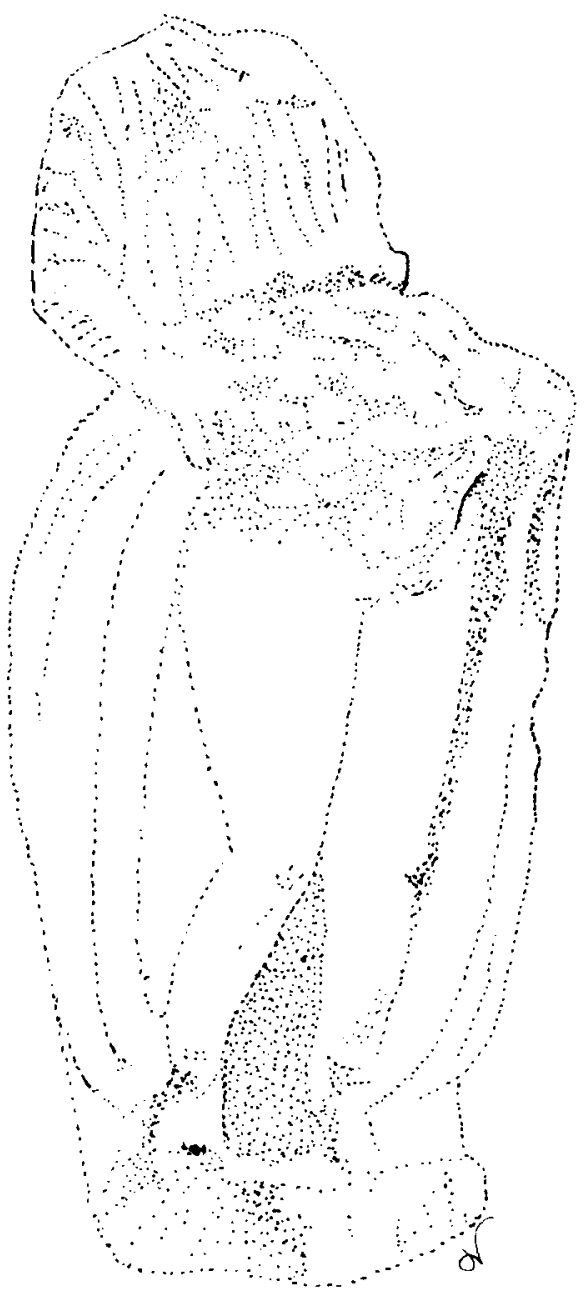

Fig. 6. Príapo. Mármol blanco. A.0,44 metros. Procede de Linares (Jaén). En Madrid, Museo Arqueológico Nacional número inventario 16.794. Se trata de una estatuilla de mediana factura. Le falta la cabeza. 
Esta tesis es también muy significativa en las obras de J. de Encarnaçao ${ }^{45}$.

En cuanto a la imprecisión de la fórmula $D$ (is) $D$ (eabusque) Silvanis hay que tener en cuenta lo que Bayet califica de falta inicial de imaginación plástica y sexual en los romanos en lo que se refiere a sus divinidades ${ }^{46}$. Al contrario que los griegos, los latinos no manifiestan la necesidad de precisar la forma ni de utilizar las posibilidades genéticas de sus dioses. Así, por precaución o indiferencia, invocan a la divinidad "masculina o femenina" (sive deus sive dea) o "a los dioses y las diosas" (diis deabusque, como en esta ocasión y otras muchas en la epigrafía religiosa hispana, agrupando los dioses, no solo por parejas sino por grupos o por duplicaciones funcionales como Liber-Libera y CerusCeres o por alianzas político-sociales, como Júpiter-Marte-Quirino o la Triada Capitolina: Júpiter, Juno y Minerva). Y señala también este autor en otro momento de su obra ${ }^{47}$, que las debilidades de la imaginación mítica de los latinos no estaban hechas para ayudar a la antropomorfización, no estando excluido que su religión, como otras, haya conocido un estadio primordial bisexuado, aunque más revelan la indiferencia a una precisión formal. Así pués, no es extraña la aparición de variantes en la epigrafía dedicada a Silvano o su advocación con los dioses y las diosas que puede tener también relación con divinidades orientales, como vemos en la inscripción dedicada a los Numina Lapitearum, del siglo ${ }^{48}$, aunque otra opinión estableceria el indigenismo de estas dedicaciones a

45 "Divinidades indigenas peninsulares: problemas metodológicos do seu estudo", Estudio sobre la Tabula Siarensis. Madrid, 1988, 261 ss, págs. $305-310 \mathrm{cfr}$. nota 53 infra. ENCARNAÇAO, J. DE, "Omissâo dos teónimos em inscriçôes votivas", STVDIA PALAEOHISPANICA, Actas del IV Coloquio sobre lenguas y culturas paleohispánicas. Victoria/Gasteiz 1987 (Veleia 2-3) Sobre deus, dfr. Raepsaet-ChaRLIER, M. T., "La datation des inscriptions latines dans les provinces occidentales de l'Empire Romain d'aprés les formules in $H$ (onorem) D(omus) D(ivinae) et Deo, Deae, ANRW II, 3, 1975, pág. 222-228.

46 BAYET, J., Histoire politique et psychologique de la religion romaine. Paris, Payot, 1969, 2, pág. 49

47 BAYET, op. cit, pág. 112.

48 Blazouez, J. M.a Imagen y Mito. Madrid, ed. Cátedra 1977, págs. 373 y 382 . También García Y BELLIDO, A., "El culto a Serapis en la Península Ibérica", BRAH 139, 1956. págs. 327 y ss. : LAMBRino, S., "Les divinités orientales en Lusitania et le sanctuaire de Panóias", BEP 17, 1953, 106 Ss. ; Rusell CORTEZ, F., "Panoias, cividade dos Lapiteas", en Anais do Instituto do vinho do Porto, 1947. También sobre Serapis cfr. GonzALEz WAG. NER, C. y AlvaR, J. "El culto de Serapis en Hispania", Symposio sobre la religion romana en Hispania. Madrid, 1981, págs. 321-334; sobre las religiones mistéricas en general, además del libro de GaRcía Y BELLIDO, A., Les religions orientales dans l'Empire romain. Leiden 1967, cfr. la comunicación de BENDALA, M., en dicho Symposio, además del articulo de este autor en ANRW. Sobre Mithra cfr. MUNOZ GaRCIA-VASCO, J.: Mitra en Hispania. Caracteres especificos. Tesis Doctoral inédita. Madrid, UNED, 1989. 


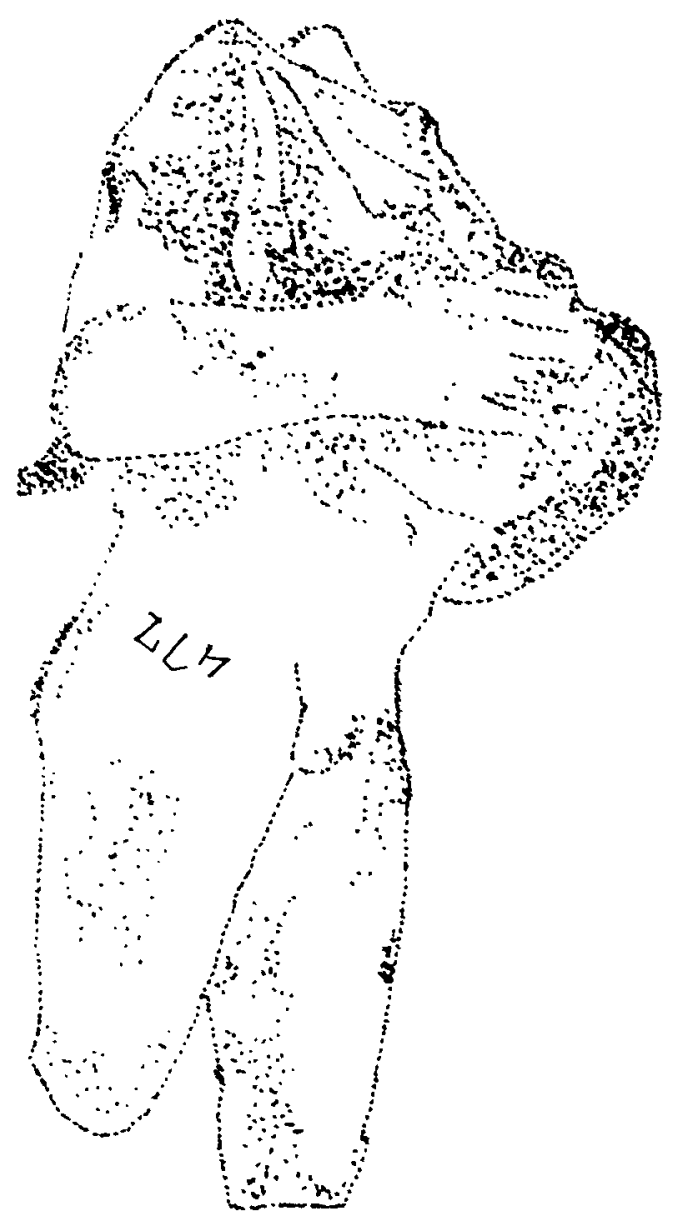

Fig. 7. ¿Silvano? García y Bellido, A.: Esculturas, número 105, lámina 83.

los dioses y las diosas, asimilables a los Lares y a las Ninfas para Leite de Vasconcelos ${ }^{49}$ bastante abundantes en el Imperio romano ${ }^{50}$ e Hispania. Asi, conocemos la inscripción de Plasencias dedicada a Dibu et

49 Leite de Vasconcelos, J., Religiôes da Lusitania II, pág. 185; Blazouez, J. M. a; “El sincretismo en la religión romana entre las religiones indigenas, griega, romana, fenicia y mistéricas"; Symposio sobre la religión romana en Hispania. Madrid 1981, págs. 179-221, pág. 202.

${ }_{50}$ Diis Deabusque Daciarum, CIL II, 996; Diis Deabusque /p/raesidibus /p/rovinciarum, 


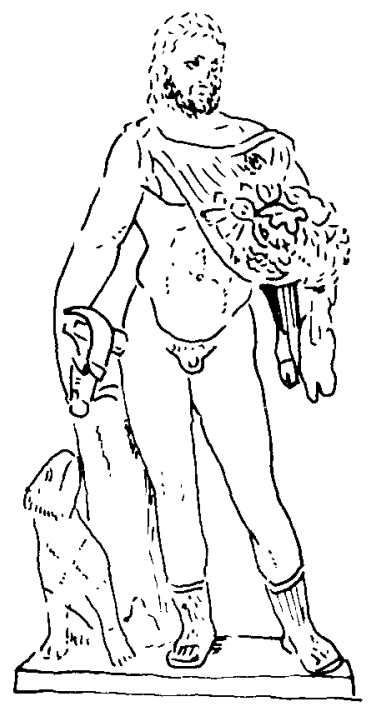

Fig. 8. Estatua de Silvano, sg. Hild, número 6.461.

Debu, forma contracta desconocida en otras ocasiones ${ }^{51}$ cuya forma arcaica con $s$ ha aparecido en Scallabis ${ }^{52}$. Otras veces se hace mención en la dedicación al Señor y la Señora, Dominus et Domina, en nominativo, $\sin$ el nombre de las divinidades, como en el caso de una inscripción de Cádiz ${ }^{53}$ :

\section{Dominus/et Domina/S.B.M. / I.Aelius/ Rocianus}

\section{LAS FUENTES ARQUEOLOGICAS}

Las esculturas en las que aparece Silvano en Hispania son escasas, posiblemente porque como divinidad de los campos, de la vida agreste y

C/L XIII, 8776, cfr. también el trabajo de ALVAR, J.: "Sine deus, sine dea" en Numen 32 , 1985, págs. 236-273.

51 Melida, J. R., Catálogo Monumental de España, Cáceres, pág. 191; Blazouez, J. M. ${ }^{\text {, }}$ Religiones primitiva de Hispania. Roma 1962, pág. 129.

Dibus Santarem, Portugal, CIL II, 325) y en Cangas de Onís (Asturias). La fórmula arcaica 53 Deabus se repite ocho veces en aras de Barcelona, como CIL II, 4496.

${ }^{53}$ CIL II 1749; CMCádiz pág. 135; ILER 5088, RRH II, pág. 647, núm. 1. Recogemos aqui diez inscripciones más y entre ellas la Lex Ursonensis, 70 , en la que se alude a la obligación de los duouiri municipales de organizar munus lu/dosue scaenicos loui lunoni 


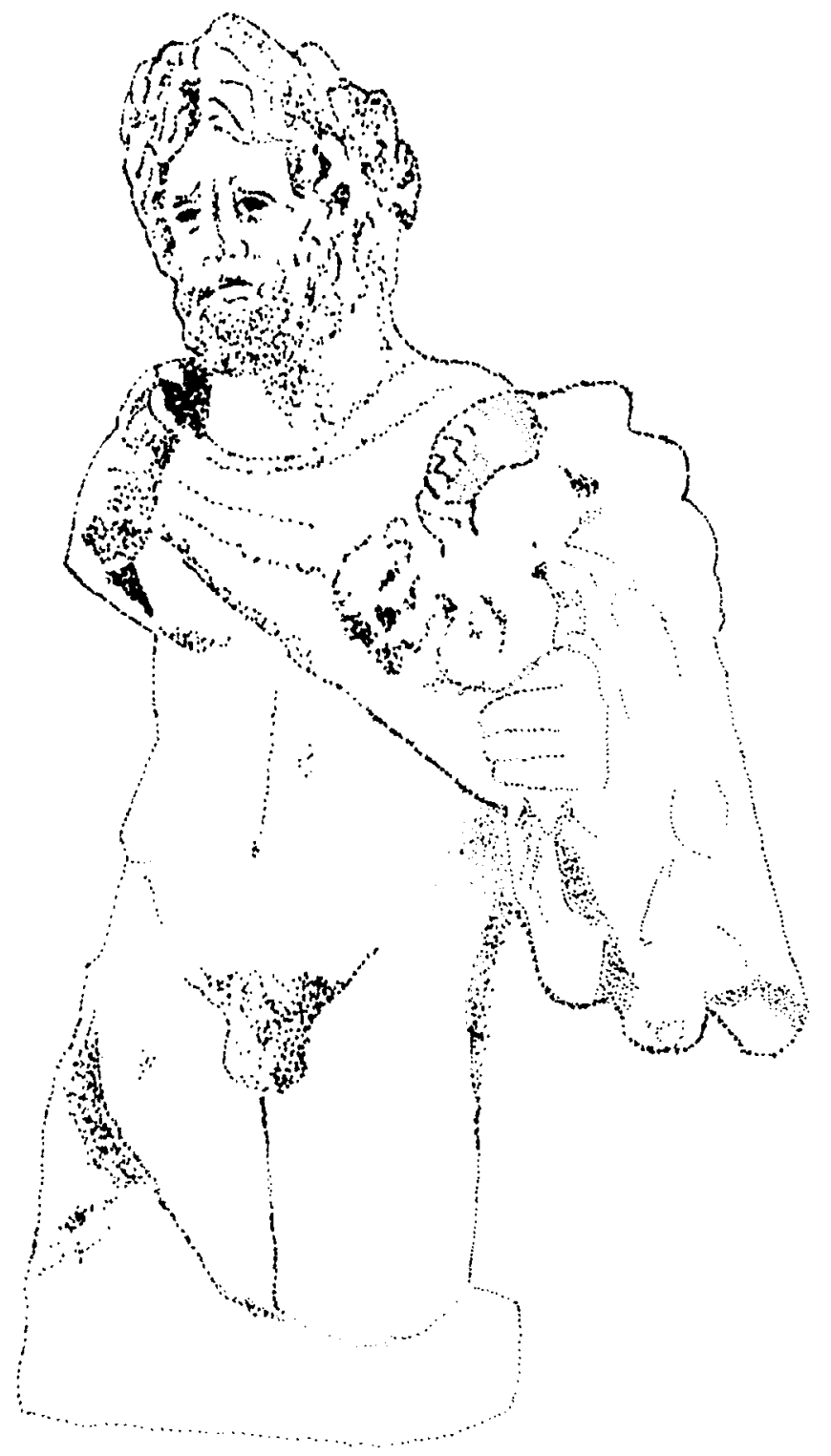

Fig. 9. Silvano. Museo Arqueológico Nacional, Madrid, número inventario 2.704. Garcia y Bellido, A.: Esculturas, número 106, lámina 84. 
de la fecundidad, a veces su ámbito iconográfico fue ocupado por divinidades próximas como los Lares o Priapo, con los que a veces puede ser confundido, con la sola diferencia, a veces, de que los Lares son representados por estatuas de jóvenes imberbes, mientras que Silvano suele Ser viejo y llevar barba y que Priapo se caracteriza por el gran falo, además de no llevar por los hombros la piel de cabra que suele llevar Silvano. Así sucede con la estatuta que García y Bellido incluye en su catálogo ${ }^{54}$, de la que se pregunta si puede o no ser Silvano, sin dar más detalles (Fig. 7). Al representar una divinidad desnuda en su parte inferior, cubiertos los hombros con la piel de una cabra que le sive de recipiente para frutos, con los genitales fraccionados diferentes al gran falo priápico, es lógico que este autor se pregunte si se trata de una escultura de Silvano ${ }^{55}$.

Según Hild, el tipo de Silvano en el arte romano nació bajo la influencia helénica y a veces se le confunde con Júpiter Ruminus. También se le confunde iconográficamente con Vertumno. Entre los ejemplos más famosos se encuentra el que le representa barbado, de pie, desnudo, tapados solo los hombros por un manto que es la piel de una cabra que le sirve de recipiente para diferentes frutos y en la derecha una pequeña hoz, como un jardinero, (Fig. 8) parecida a la que se encuentra en el Museo Arqueológico de Madrid, n. ${ }^{\circ}$ inv. $2.704^{56}$ (Fig. 9) con las diferencias apreciables de que esta, de la que no se sabe si es procedente de Mérida o Itálica (Santiponce, Sevilla) mira para otro lado y está incompleta, por lo que no sabemos si a sus pies iba o no un perro. Lleva el pecho cubierto con una piel de animal que monta el brazo izquierdo, sirviéndole de recipiente para un gran manojo de frutos, entre los que se identifican piñas, manzana, uvas, higos, y espigas. La mano izquierda agarra, en el caso del ejemplar del Museo Arqueológico de Madrid, una de las manos

\footnotetext{
Minervae deis/deabusq(ue) quadriduom m(aiore) p(arte) diei quot eius fie/ri poterit. CIL II. 5439; Dessau, 6087; DÓRS, A., Epigrafia juridica de la España romana. Madrid 1953, pág. 194. También sobre el significado de la omisión de los teónimos, cfr. EnCARnaCAO, J., "Omissâo dos teónimos em inscriçoes votivas", Veleia 2-3, 1985-86, págs. 305-310, para quien la omisión de los teónimos en las dedicaciones puede significar la existencia de santuarios, en los que no hacia falta especificar los nombres de los dioses. Sin embargo, creo que cuando se hace alusión a dibus deabusque a continuación de los nombres de otras divinidades, lo que se está haciendo es incluir en la dedicatoria "a los innumerables dioses y diosas del panteón romano", de los cuales unos tienen nombre y otros no.

105 Garcia y Bellido, A., Esculturas romanas de España y Portugal. Madrid 1949, núm. 105 lám. 83.

${ }^{55}$ Aunque no da más detalles, de los que dice que carece al corregir el libro ya en segundas pruebas, por lo que ignoramos la situación y procedencia de la pieza, así como con su cronologia.

${ }^{56}$ Garcia y Bellido, A., Esculturas, núm. 106, lám. 84.
} 


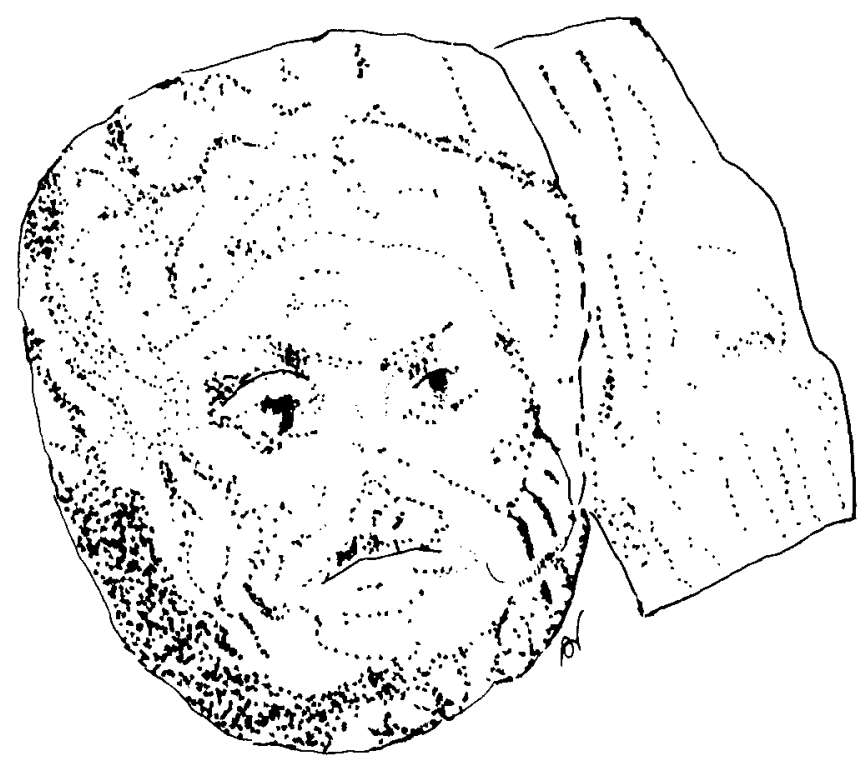

Fig. 10. Cabeza de Silvano. Elorza, J. C.: Esculturas romanas en La Rioja. Logroño, 1975, página 30. Apareció en Varea (Logroño).

delanteras de la piel del animal, mientras que en la otra empuñaría una pequeña hoz como suele ser corriente en otras representaciones del dios. El muslo derecho conserva restos de adherencias que probablemente pertenece al tronco del árbol que debía servir de apoyo a la estatua, al ie de la cual debemos figurarnos que estaría un perro mirando a su mano..

También coronado con una corona de piñas, como la conservada en Madrid, además de hojas de pino, está la cabeza hallada en Varea (Logroño) ${ }^{57}$ aunque esta presenta una iconografía distinta, la corona es más cuadrada y al lado izquierdo de la cabeza hay restos de un árbol, una conifera cargada de piñas (Fig. 10). Otro ejemplar un torso fraccionado, de mármol que puede ser Silvano, por la piel de cabra que lleva en el brazo izquierdo, de la que se aprecian claramente los cuernos, es el que pertenece a la Colección de la Sra. Condesa de Lebrija, por lo que tal vez proceda de Itálica.

${ }^{57}$ Elorza, J. C., Esculturas romanas en la Rioja. Logroño 1975, págs. 30-33, figs. en págs. 31 y 33 . 


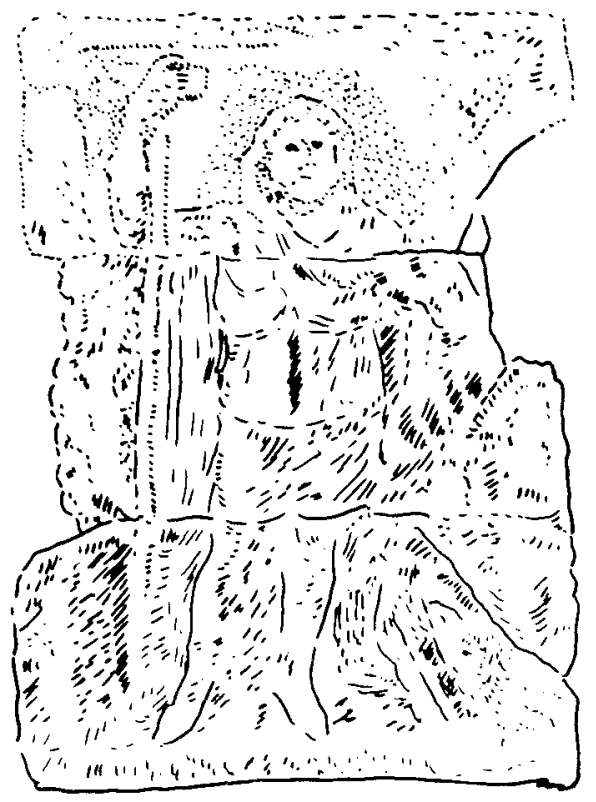

Fig. 11. Figura del dios Silvano, con martillo o maza y un perro. Hild número 6.460 .

Otros monumentos nos muestran la asociación o identificación de Silvano con el dios del mazo o del martillo céltico (Fig. 11) que no es otro que Thor-Taranis-Donar, también identificado con Júpiter o Vulcano $y$ otras veces, como en los altares de Rottenburg y de Wildberg, el dios se asemeja a Diana cazadora, por la compañia del perro, estando además vestido, por lo que de tener la mano que sujeta el martillo fracturada sería muy dificil identificarle con Silvano. También le vemos representado en compañía del Sol y la Luna en un relieve del Museo Capitolino. Se trata de un relieve votivo de $0,35 \mathrm{~m}$. de alto por 0,28 de lado, de marmol griego, descubierto en Roma (Fig. 12). El Sol tiene la cabeza rodeada por nueve rayos y la Luna está representada con un creciente sobre la cabeza. Aquí se trata de personificaciones romanas o greco-romanas del sol y la luna pero en muchos casos representan divinidades sirias, como el Sol (= Malakbelos) en el altar de Palmira de la Stanza Terrene a Sinistra ${ }^{58}$. La inscripción ${ }^{59}$ está dedicada por los miembros de una cella

\footnotetext{
${ }^{58}$ Para Silvano en conexión con cultos orientales cfr. Cumont, F., en Rev. Arch., XIX, 1892, págs. 186 ss

CIL VI, 706 = DESSAU 3941.
} 




Fig. 12. Relieve votivo de mármol. H. 0,35 metros. Mármol griego. La inscripción (CIL VI 706) ocupa la mayor parte del relieve. H. Stuart Jones, M. A. (ed.): A catalogue of the Ancient Sculptures preserved in the Municipal Collection of Rome. The Sculpture of the Museo capitolino, Oxtord, Clarendon Prres 1912, platers, pl 84, 30, o en la stanza del Fauno. Texto en el tomo correspondiente, página 33.

familiaris o cella servorum ${ }^{60}$, con to que nuevamente, como en las inscripciones hispanas, tenemos al dios en relación con las bajas clases sociales, hecho que hemos constatado no es tan evidente al estudiar el culto de Diana en nuestra Península, salvo si se quiere, en el caso concreto de las inscripciones de Segóbriga (Cuenca).

${ }^{60} \mathrm{H}$. Stuart Jones, M. A. (ed), A catalogue of the Ancient Sculptures preserved in the Municipal Collection of Rome. The Sculpture of the Museo Capitolino. Oxford. Clarendon Press 1912, plates, pl. 84, 30, o, en la stanza del Fauno. Texto en el tomo correspondiente pág. 33. 